\title{
Evaluation of Water Resources Carrying Capacity in Shandong Province Based on Fuzzy Comprehensive Evaluation
}

\author{
Qiang Zhao, Qian Gao, Mingyue Zhu, and Xiumei Li* \\ School of Water Conservancy and Environment, University of Jinan, Jinan 250022, China
}

\begin{abstract}
Water resources carrying capacity is the maximum available water resources supporting by the social and economic development. Based on investigating and statisticing on the current situation of water resources in Shandong Province, this paper selects 13 factors including per capita water resources, water resources utilization, water supply modulus, rainfall, per capita GDP, population density, per capita water consumption, water consumption per million yuan, The water consumption of industrial output value, the agricultural output value of farmland, the irrigation rate of cultivated land, the water consumption rate of ecological environment and the forest coverage rate were used as the evaluation factors. Then,the fuzzy comprehensive evaluation model was used to analyze the water resources carrying capacity Force status evaluation. The results showed : The comprehensive evaluation results of water resources in Shandong Province were lower than 0.6 in 2001-2009 and higher than 0.6 in 2010-2015, which indicating that the water resources carrying capacity of Shandong Province has been improved.; In addition, most of the years a value of less than 0.6 , individual years below 0.4 , the interannual changes are relatively large, from that we can see the level of water resources is generally weak, the greater the interannual changes in Shandong Province.
\end{abstract}

\section{Introduction}

Water resources carrying capacity refers to the specific areas within the premise of a certain level of living production and the ecological function of water environment subsystem, through scientific and reasonable distribution measure, the maximum capacity to support the needs of the population, social, economic and ecological environment that the water supply can provide[1-5]. Shandong province is one of the northern water shortage regions. Based on Shandong province economic-socio-environment basic research date from 2001 to 2015, the application of fuzzy comprehensive evaluation model to evaluate the water resources carrying capacit, which aimed to provide a basis for the rational development and utilization of water resources in the leap-forward development of Shandong province.

\section{Overview of Water Resources in the Study Area}

Shandong province is located in the eastern seaboard of China, the northernmost end of east China area, there are three drainage areas of Yellow River, huai river and hai river. Precipitation is the main water resources in Shandong, and is greatly affected by rainfall. The Yellow River is the main external water source in Shandong, and the nansi lake is the largest lake in Shandong province. The average annual precipitation of the whole province is $679.5 \mathrm{~mm}$, and the yearly average total water resources is 30582 million $\mathrm{m}^{3}$; The per capita water resource is $344 \mathrm{~m}^{3}$, less than $1 / 6$ of the national average, and 1/25 of the world average, the third lowest per capita water resources in all provinces (cities and autonomous regions). According to the international water shortage standard, per capita water resource occupancy less than $500 \mathrm{~m}^{3}$ would be considered as extreme water shortage area. While Shandong is only $344 \mathrm{~m}^{3}$ per capita, which shows that Shandong is in extreme water shortage.

\section{The Construction of Fuzzy Comprehensive Evaluation Model}

The fuzzy comprehensive evaluation method can provide an effective way for the research of regional water resources carrying capacity, the essence of this method is to affect the carrying capacity of water resources, on the basis of single factor evaluation, through comprehensive evaluation matrix expansion multi-factor comprehensive evaluation of water resources carrying capacity, thus it is concluded that the size of the water resources carrying capacity. In this paper, the fuzzy comprehensive evaluation model was applied to evaluate the overall water carrying capacity of Shandong province.

\subsection{The Selection of Evaluation Factors, Classification and Grading}

\footnotetext{
* Corresponding author: Xiumei Li@stu_lixm@ujn.edu.cn
} 
According to the characteristics of regional water resources, referring to the analysis of supply and demand of water resources in the index system, on this basis, fully considered the differences between the stock of natural water resources assigned and the different way of development, and used the water resources supply and demand analysis index system of the national and Shandong province as the basis, the evaluation index was divided into three levels (table 1). In this paper, the carrying capacity of water resources was divided into 3 levels, and the $V_{1}$ level is excellent, which indicates that the water resources in this region still have a large carrying capacity, and the water resources supply is adequate. The $V_{3}$ level is poor, which indicates that water resources carrying capacity is to allow the lowest, it is difficult to develop in depth, has restricted the social economy and stable development; the $V_{2}$ level status is somewhere in between, which indicates that this region basically can adapt to the economic development of the basin water resources, water resources development and utilization to the larger size, but still has certain potential of development and utilization.

Table.1 Rating Criteria for Each Evaluation Index

\begin{tabular}{|c|c|c|c|c|c|}
\hline $\begin{array}{l}\text { Index } \\
\text { layer }\end{array}$ & Rule layer & Index layer & $V_{1}$ & $V_{2}$ & $V_{3}$ \\
\hline \multirow{15}{*}{$\begin{array}{l}\text { Water } \\
\text { resource } \\
\text { s } \\
\text { carrying } \\
\text { capacity } \\
O\end{array}$} & \multirow{4}{*}{$\begin{array}{l}\text { Water resources } \\
\text { condition } \\
A_{1}\end{array}$} & $\begin{array}{l}\text { Per capita water resources } U_{1} \\
\qquad\left(\mathrm{~m}^{3} / \text { per }\right)\end{array}$ & $>600$ & $300 \sim 600$ & $<300$ \\
\hline & & $\begin{array}{c}\text { utilization rate of water resources } \\
(\%)\end{array}$ & $<30$ & $30 \sim 80$ & $>80$ \\
\hline & & $\begin{array}{l}\text { Water supply modulus } U_{3} \text { （ten } \\
\left.\text { thousand } \mathrm{m}^{3} / \mathrm{km}^{2}\right)\end{array}$ & $>39$ & $15 \sim 39$ & $<15$ \\
\hline & & precipitation $U_{4}(\mathrm{~mm})$ & $>800$ & $500 \sim 800$ & $<500$ \\
\hline & \multirow{8}{*}{$\begin{array}{l}\text { Socio-economic } \\
\text { condition } \\
A_{2}\end{array}$} & $\begin{array}{c}\text { Per capita GDP } U_{5} \quad \text { (ten thousand } \\
\text { yuan })\end{array}$ & $>4$ & $2 \sim 4$ & $<2$ \\
\hline & & Per capita density $U_{6} \quad\left(\mathrm{a} / \mathrm{km}^{2}\right)$ & $<550$ & $550 \sim 700$ & $>700$ \\
\hline & & $\begin{array}{c}\text { Water consumption per capita. } \\
\left(\mathrm{m}^{3}\right)\end{array}$ & $<30$ & $30 \sim 100$ & $>100$ \\
\hline & & $\begin{array}{l}\text { Water consumption of ten thousand } \\
\text { yuan. } u_{8} \quad\left(\mathrm{~m}^{3} / \text { ten thousand yuan }\right)\end{array}$ & $<70$ & $70 \sim 200$ & $>200$ \\
\hline & & Water consumption of industrial & & & \\
\hline & & $\begin{array}{l}\text { output of ten thousand yuan. } u_{9} \\
\left(\mathrm{~m}^{3} / \text { ten thousand yuan }\right)\end{array}$ & $<180$ & $80 \sim 500$ & $>500$ \\
\hline & & Water consumption of agricultural & & & \\
\hline & & $\begin{array}{l}\text { output of ten thousand yuan. } u_{10} \\
\left(\mathrm{~m}^{3} / \text { ten thousand yuan }\right)\end{array}$ & $<400$ & $400 \sim 1000$ & $>1000$ \\
\hline & \multirow[b]{2}{*}{$\begin{array}{l}\text { Ecological } \\
\text { environmental } \\
\text { conditions }\end{array}$} & Arable irrigation rate $u_{11}(\%)$ & $>80$ & $40 \sim 80$ & $<40$ \\
\hline & & $\begin{array}{l}\text { Water rate of ecological } \\
\text { environment. } U_{12}(\%)\end{array}$ & $>5$ & $1 \sim 5$ & $<1$ \\
\hline & $A_{3}$ & Forest coverage rate $U_{13} \quad(\%)$ & $>35$ & $10 \sim 35$ & $<10$ \\
\hline
\end{tabular}

To better reflect the level of water resources carrying capacity, to take 1 point of numerical evaluation level:

$a_{1}=0.05, a_{2}=0.5, a_{3}=0.95$, after quantification can quantitatively reflect the level degree of the influence of the carrying capacity factors, the higher the value, the greater the water resources development capacity. According to the value of $a_{j}$ and the value of membership $b_{j}$ in $B$ matrix, the comprehensive evaluation score of water resources carrying capacity in the comprehensive evaluation matrix $B$ was calculated according to formula (1).

$$
a=\frac{\sum_{j=1}^{3} b_{j} a_{j}}{\sum_{j=1}^{3} b_{j}}
$$

In the formula, $a$ is the comprehensive evaluation value of water resources carrying capacity based on the comprehensive evaluation result matrix $B$. 


\subsection{The Calculation of the Evaluation Matrix}

According to the actual value of each evaluation factor, the value of the subordinate function $\gamma_{i}$ of the judging matrix was evaluated by comparing the classification index. Fuzzy processing was used to construct membership function to smooth transition between all

levels. For the evaluation factors $\gamma_{1}, \gamma_{2}$ and $\gamma_{3} \ldots .$. the evaluation grade membership function was calculated as follows:

$$
\begin{aligned}
& \gamma_{1}=\left\{\begin{array}{cc}
0.5\left(1+\frac{k_{1}-u_{1}}{k_{2}-u_{1}}\right) & u_{1}>k_{1} \\
0.5\left(1-\frac{u_{1}-k_{2}}{k_{2}-k_{1}}\right) & k_{2}<u_{1} \leq k_{1} \\
0 & u_{1} \leq k_{2}
\end{array}\right. \\
& \gamma_{2}=\left\{\begin{array}{cc}
0.5\left(1-\frac{k_{1}-u_{1}}{k_{2}-u_{1}}\right) & u_{1}>k_{1} \\
0.5\left(1+\frac{u_{1}-k_{2}}{k_{2}-k_{1}}\right) & k_{2}<u_{1} \leq k_{1} \\
0.5\left(1+\frac{k_{3}-u_{1}}{k_{2}-u_{1}}\right) & k_{3}<u_{1} \leq k_{2} \\
0.5\left(1-\frac{k_{3}-u_{1}}{k_{3}-k_{2}}\right) & u_{1} \leq \mathrm{k}_{3}
\end{array}\right. \\
& \gamma_{3}=\left\{\begin{array}{cc}
0.5\left(1+\frac{k_{3}-u_{1}}{k_{2}-u_{1}}\right) & u_{1} \leq k_{3} \\
0.5\left(1-\frac{u_{1}-k_{3}}{k_{2}-k_{3}}\right) & k_{3}<u_{1} \leq k_{2} \\
0 & u_{1}>k_{2}
\end{array}\right.
\end{aligned}
$$

Where: ${ }^{k}$ is the critical value of the evaluation level $V_{1}$ and $V_{2} ; k_{3}$ is the critical value of rating $V_{2}$ and $V_{3}$; $k_{2}$ is the midpoint of the evaluation level $V_{2}$. The critical value of each evaluation level corresponding to each indicator was shown in table 1.

\subsection{Calculation of Index Weight}

First of all, according to the index level of the partition, referring to China's water resource evaluation standard, the "1-9" scale method commonly used in AHP [6-8], was adopted to construct the judgment data matrix. Secondly, according to the judgement matrix, used the mathematical matrix to calculate the importance of the indicator layer $(U)$ relative to the principle layer $(A)$, the importance of the criterion layer relative to the target layer $(\mathrm{O})$, and then end up with a judgment matrix. Note that the water resources condition is the foundation of water resources carrying capacity, so water condition here than the social and economic condition and ecological environment condition more important, got $3: 1: 1$. Finally, the weight of the indicator layer to the principle layer multiplied by the weight of the principle layer to the target layer, so the weight of the indicator layer to the target layer was obtained ( $W$ ), and the weight calculation results can be gotten.

\subsection{Calculation of Comprehensive Evaluation of Water Resources Comprehensive Capacity}

According to the weight vector $W$ and the judgment matrix $R$ calculated above, the calculation formula for comprehensive evaluation result of the water carrying capacity is as follows:

$$
B=W \times R=\left[\begin{array}{llll}
W_{1} & W_{2} & \bullet & W_{13}
\end{array}\right] \times\left[\begin{array}{ccc}
\gamma_{11} & \gamma_{12} & \gamma_{13} \\
\gamma_{21} & \gamma_{22} & \gamma_{23} \\
\bullet & \bullet & \bullet \\
\gamma_{13,1} & \gamma_{13,2} & \gamma_{13,3}
\end{array}\right]=\left[\begin{array}{lll}
b_{1} & b_{2} & b_{3}
\end{array}\right]
$$

\section{Integrate Assessment of Water Resource Carry Capacity in Shandong Province}

According to the evaluation index of carrying capacity of table 1, the evaluation index of water resources carrying capacity in Shandong province was quantified. Through formula (2) (3) (4), we can find the values of each index belonging to $V_{1}, V_{2}$ and $V_{3}: \gamma \mathrm{il}, \gamma \mathrm{i}$ and $\gamma \mathrm{i} 3$. The calculated results of each year were in the form of a matrix, which referred to the total number of fifteen matrices, namely [ $\gamma \mathrm{i} 1 、 \gamma \mathrm{i} 2$ 和 $\gamma \mathrm{i} 3]$, which was $\mathrm{R}$. The results in 2002, 2005 and 2015 were shown in table 2.

Table.2 Each Indicator Corresponds to Each Level of Membership of Shandong Province in 2001、2005、2010、2015

\begin{tabular}{cccccccccccccc}
\hline Iindic & \multicolumn{3}{c}{2001} & \multicolumn{1}{c}{2005} & \multicolumn{2}{c}{2010} & \multicolumn{2}{c}{2015} \\
\cline { 2 - 11 } \\
ators & $\gamma_{\mathrm{i} 1}$ & $\gamma_{\mathrm{i} 2}$ & $\gamma_{\mathrm{i} 3}$ & $\gamma_{\mathrm{i} 1}$ & $\gamma_{\mathrm{i} 2}$ & $\gamma_{\mathrm{i} 3}$ & $\gamma_{\mathrm{i} 1}$ & $\gamma_{\mathrm{i} 2}$ & $\gamma_{\mathrm{i} 3}$ & $\gamma_{\mathrm{i} 1}$ & $\gamma_{\mathrm{i} 2}$ & $\gamma_{\mathrm{i} 3}$ \\
\hline$U_{1}$ & 0 & 0.404 & 0.597 & 0 & 0.999 & 0.001 & 0 & 0.576 & 0.424 & 0 & 0.269 & 0.731 \\
\hline
\end{tabular}




\begin{tabular}{cccccccccccccc}
\hline$u_{2}$ & 0 & 0.738 & 0.262 & 0.962 & 0.038 & 0 & 0.818 & 0.182 & 0 & 0.530 & 0.470 & 0 \\
$u_{3}$ & 0 & 0.546 & 0.454 & 0.603 & 0.397 & 0 & 0 & 0.468 & 0.532 & 0 & 0.446 & 0.554 \\
$u_{4}$ & 0 & 0.836 & 0.164 & 0.533 & 0.467 & 0 & 0.654 & 0.346 & 0 & 0 & 0.752 & 0.248 \\
$u_{5}$ & 0 & 0.256 & 0.744 & 0.000 & 0.499 & 0.502 & 0.550 & 0.451 & 0 & 0.854 & 0.146 & 0 & 0.493 \\
$u_{6}$ & 0.828 & 0.172 & 0 & 0.740 & 0.260 & 0 & 0.599 & 0.401 & 0 & 0.507 & 0.493 \\
$u_{7}$ & 0.988 & 0.012 & 0 & 0.582 & 0.418 & 0 & 0.550 & 0.450 & 0 & 0.551 & 0.449 & 0 \\
$u_{8}$ & 0 & 0.245 & 0.755 & 0.660 & 0.341 & 0 & 0.586 & 0.414 & 0 & 0.679 & 0.321 & 0 \\
$u_{9}$ & 0 & 0.275 & 0.725 & 0.862 & 0.138 & 0 & 0.680 & 0.320 & 0 & 0.735 & 0.265 & 0 \\
$u_{10}$ & 0 & 0.136 & 0.864 & 0 & 0.444 & 0.556 & 0.656 & 0.344 & 0 & 0.947 & 0.053 & 0 \\
$u_{11}$ & 0.655 & 0.345 & 0 & 0.676 & 0.324 & 0 & 0.562 & 0.438 & 0 & 0.692 & 0.308 & 0 \\
$u_{12}$ & 0 & 0.397 & 0.603 & 0 & 0.530 & 0.470 & 0 & 0.773 & 0.228 & 0.560 & 0.440 & 0 \\
$u_{13}$ & 0 & 0.852 & 0.148 & 0.560 & 0.440 & 0 & 0.600 & 0.400 & 0 & 0 & 0.732 & 0.268 \\
\hline
\end{tabular}

Table.3 Comprehensive Evaluation Results of Water Resources Carrying Capacity

\begin{tabular}{lcccc}
\hline$B$ value & $b_{1}$ & $b_{2}$ & $b_{3}$ & $a$ \\
\hline 2001year & 0.0266 & 0.5249 & 0.4485 & 0.3101 \\
2002year & 0.0652 & 0.3142 & 0.6205 & 0.2501 \\
2003year & 0.4031 & 0.4048 & 0.192 & 0.595 \\
2004year & 0.3395 & 0.4341 & 0.2263 & 0.5509 \\
2005year & 0.3752 & 0.5032 & 0.1216 & 0.6141 \\
2006year & 0.2114 & 0.461 & 0.3275 & 0.4477 \\
2007year & 0.3446 & 0.5116 & 0.1438 & 0.5904 \\
2008year & 0.3477 & 0.4784 & 0.1739 & 0.5782 \\
2009year & 0.3184 & 0.4704 & 0.2112 & 0.5482 \\
2010year & 0.3833 & 0.4744 & 0.1423 & 0.6085 \\
2011year & 0.4656 & 0.4132 & 0.1211 & 0.6550 \\
2012year & 0.453 & 0.3602 & 0.1867 & 0.6198 \\
2013year & 0.3848 & 0.4348 & 0.1803 & 0.5920 \\
2014year & 0.1485 & 0.442 & 0.4094 & 0.3825 \\
2015year & 0.3668 & 0.3921 & 0.241 & 0.5566 \\
\hline
\end{tabular}

By the data in table 2 and formula (1) to (5) for carrying capacity of water resources in Shandong province comprehensive evaluation results were shown in table 3. For example, in 2014, the comprehensive evaluation result set $\mathrm{B}=[0.1485,0.442,0.4094]$, and the comprehensive ability $\mathrm{a}=0.3825$, which shown that the capacity of water resources in Shandong province was not optimistic in 2014. It was not difficult to see the annual rainfall data of Shandong province in 2014, and the water resources capacity of Shandong province was very weak. But the value of $B$ control was in good condition of $b_{2}>b_{3}$, which indicated that a series of protective measures in recent years had effectively avoided the problem of insufficient carrying capacity of water resources brought by the climate problem, and improved the threat defense capability posed by natural disasters.

The change trend chart of water resources grading evaluation factor $B$ and comprehensive evaluation factor $a$ were shown in figure 1,2 . Overall, the water resources carrying capacity gradually ascending steadily at the same time, through the growth of the 2001 to 2009 , the $a$ value gradually began to more than 0.6 , the main above 0.6 in 2010-2015, which showed that Shandong province water resources carrying capacity has improved in general; The ranking coefficient $b_{2}$ remains the highest, indicated that the overall performance of water resources carrying capacity was in good condition, and the coefficient $b_{1}$ was gradually increasing at the same time, and the proportion $b_{3}$ was decreasing, it indicated that the water resource carrying capacity of Shandong province has a tendency to improve the membership of $V_{1}$, which was inseparable from the rational development of these years and scientific management. Secondly, the capacity of water resources was closely related to the amount of groundwater resources. In 2001, 2002, 2006 and 2014, the $a$ value was significantly smaller than other years, again through the Shandong province water resources statistics showed that the groundwater resources in the past few years was lower than other years, and the carrying capacity of water resources in Shandong province were associated with groundwater reserves, namely once encountered drought years (dry year), groundwater can play the main water supply capacity. 


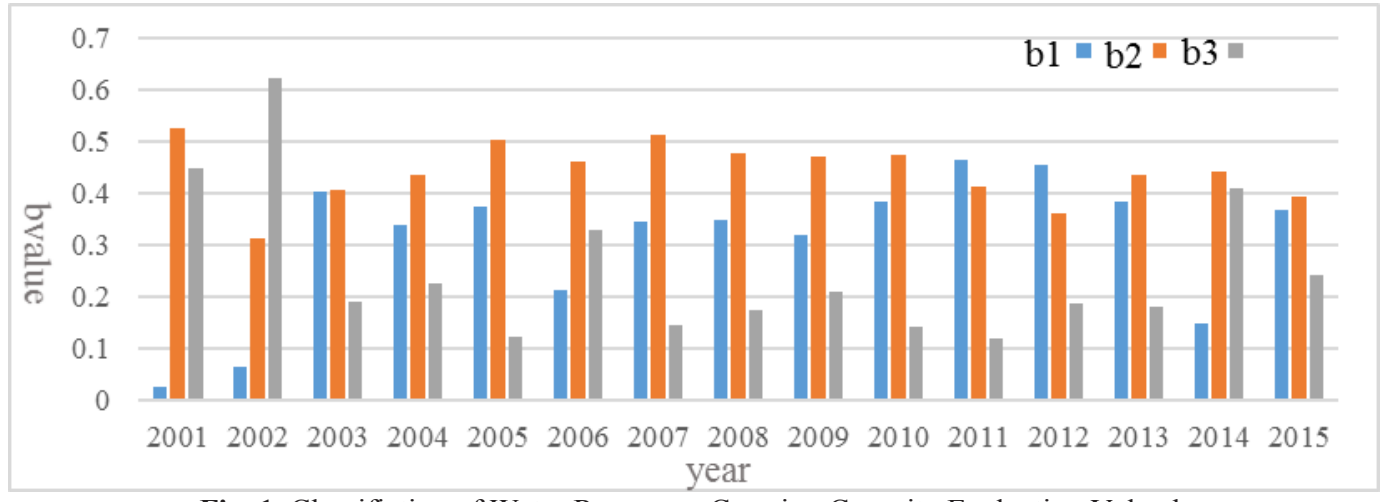

Fig. 1. Classifiction of Water Resources Carrying Capacity Evaluation Value b

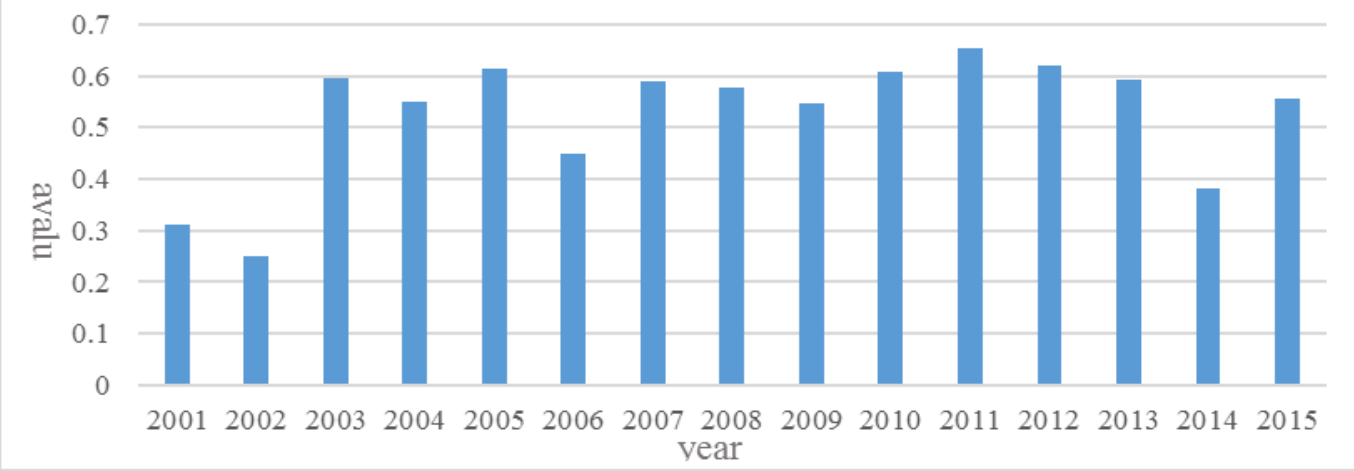

Fig. 2. Comprehensive Assessment of Water Resources Carrying Capacity Value a

\section{Conclusion}

This paper started from the characteristics of Shandong province economy-society-environmental composite system, comprehensive analyzed the main influencing factors of regional water resources carrying capacity as evaluation factors(to table 1), and the current status of water resources carrying capacity of Shandong province was evaluated by fuzzy comprehensive evaluation model. Results shown that the carrying capacity of water resources in Shandong province level gradually guaranteed, annual change gradually narrowed, but the contradiction between supply and demand of water resources is outstanding, the water shortage area is widely distributed, and in the later development should adhere to the open source throttling, pay equal attention to practical ability of to increase the supply capacity of water resources.

\section{Acknowledgements}

This study was financially supported by the Natural Science Foundation of China (NO.41471160)

\section{References}

1. Soft science research of water resources in Xinjiang province, Water Resources and Hydropower Engineering, 6:2-9 (1989) (in Chinese)

2. Y Feng, W Han, H Wang, J Lian, J Huang, Advances in Water Science, 14, 1:109-113 (2003) (in Chinese)
3. Q Duan, C Liu, X Chen, W Liu, H Zheng, Acta Geographica Sinica, 65, 1:82-90 (2010) (in Chinese)

4. Y Sun, Y Gao, Y Shi, F Xu, Water resources protection, 27, 1:20-23.( 2011) (in Chinese)

5. A Ding, D Chen, $C$ Pan, $X X u$, South-to north water diversion and water conservancy technology, 8, 3:71-73 (2010) (in Chinese)

6. Water conservancy bureau of hydraulic power department. Evaluation of water resources in China (hydraulic power press, 1987) (in Chinese)

7. J Song, Y Gu, Natural Science Journal of Harbin Normal University, 31, 1:60-62 (2015) (in Chinese)

8. J Dai, Y Pan, Q Liu, H Tang, Meteorological science, 34, 4:428-434 (2014) (in Chinese) 